\title{
空気混相流による流れの場の数值解析について
}

\section{1. 気液二相流の表現}

水力学の分野で取扱われる気液二相流は, 主として管 路内の現象を対象にしており，水平管路，傾斜管路，鉛 直管路など，それぞれについて実験的な研究が進められ ている.この場合二相流の表現は，気体，液体の容積速 度を用いるのが一般的な方法で，管路内の気体容積流 量, 液体容積流量を管路の断面積でそれぞれ割った值 $w_{g 0}, w_{l 0}$ をもって容積速度としている. これらを用い $\tau$,

$$
\left.\begin{array}{lr}
\text { 二相流の速度 } & w_{m}=w_{g 0}+w_{l_{0}} \\
\text { 気体容積流量比 } & \beta=\frac{w_{g 0}}{w_{g 0}+w_{l_{0}}}
\end{array}\right\}
$$

が parameter として使われている. また気体，液体の単 位容積重量を $\gamma_{g}, \gamma_{l}$ とするとき, 二相流の単位容積重 量 $\gamma$ は,

$$
\gamma=f_{g} \cdot \gamma_{g}+\left(1-f_{g}\right) \cdot \gamma_{l}=\gamma_{l}-f_{g}\left(\gamma_{l}-\gamma_{g}\right)
$$

と表わされる.ここで $f_{g}$ はボイド率とよばれる係数で, 二相流の容積に占める気体容積の割合を示す. ボイド率 を用いると, 気体の速度 $w_{g}$, 液体の速度 $w_{l}$ は

$$
w_{g 0}=f_{g} \cdot w_{g}, \quad w_{l 0}=\left(1-f_{g}\right) \cdot w_{l}
$$

の関係となり, 両者の速度比を $w_{g} / w_{l}=M$ とおくと

$$
f_{g}=\frac{w_{g 0}}{w_{g 0}+w_{l 0} \cdot M}=\frac{1}{1+\left(\frac{1}{\beta}-1\right) M}
$$

と表わすことができる.さらにもう一つの parameter と して，乾き度が用いられ，次のように定義されている。

$$
x=\frac{w_{g 0} \cdot \gamma_{g}}{w_{g 0} \gamma_{g}+w_{l_{0}} \cdot \gamma_{l}}
$$

貧酸素水塊の改善あるいは成層破壊を目的として，海 底の散気管から空気を放出し，空気混相流の流れを形成 させようとする場合には，上述のような管路という拘束 条件がないために，別途の方法によって各種の parameter を表わすことが必要となってこよう. 一つの方法と して, 実験水路での空気混相流の流況を数值解析から近 似させる場合，散気管の直径は数十 $\mathrm{mm}$ となっており，

* 正会員 工博 東京都立大学教授 工学部土木工学科

** 正会員東京都立大学助手 工学部土木工学科
堀口孝男*. 小坂 俊 吉**

図一1 に示すような格子網では, 散気管の左右数メート ルまでは，一辺の長さが $10 \mathrm{~cm}$ 程度の正方形格子で底 面から水面まで数值計算を実施する必要が生じてくるの で, かかる格子 1 個の容積のなかに含むれる気体容積の 割合でボイド率を定義すると, 式 (1)〜 (4) と類似した 表現が可能となろう.

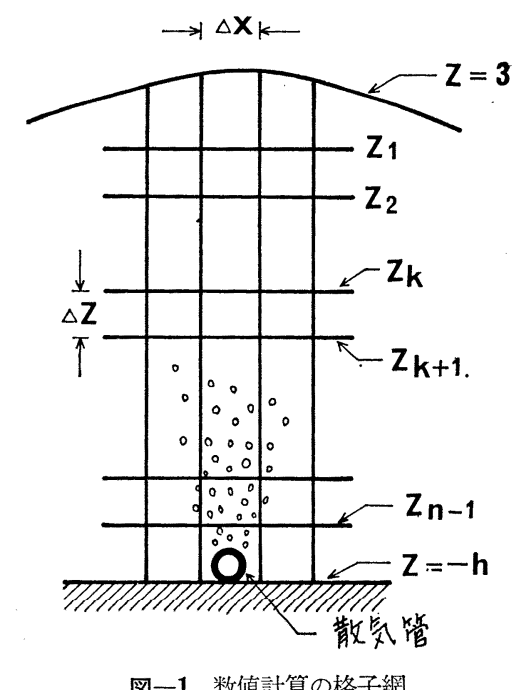

\section{2. 混相流の数値解析法}

空気混相流によって流れが形成される現象を，空気の 混入によって液体の密度が見かけ上減少しはじめ, 空気 がまだ混入していない周囲の液体との間に圧力差が生ず るため, 流れが発生してくるものと解釈して操作するの がこの数值解析の基本となっているものである. 式 (3) に対応するボイド率を格子の容積に対するとの格子内の 空気容積の割合として，これを $S$ と表わすとさ，式 (2) を $g$ で割った混相流の密度は, 液体の密度を $\rho_{w}$, 気体 の密度を $\rho_{a}$ とすれば,

$$
\rho=\rho_{w}(1-S)+\rho_{a} S \fallingdotseq \rho_{w}(1-S)
$$

と表わされる.

繁雑さを避けるために，図一1 に示すように $x$ 軸を静 水面にとり，鉛直上方に $z$ 軸をとる 2 次元の現象として 
取扱うとき，鉛直方向に 10〜20 層に分割したいわゆる レベル・モデルを用いると， $S$ を一種の拡散量とみなし て, 散気管の存在する最下層の格子では次のような拡散 式となる.

$$
\begin{gathered}
\frac{\partial}{\partial t} \int_{-h}^{z_{n-1}} S d z=-\frac{\partial}{\partial x} \int_{-h}^{z_{n-1}}(u S) d z-[w S]_{z_{n-1}} \\
+\frac{\partial}{\partial x} \int_{-h}^{z_{n-1}}\left(K_{x} \frac{\partial S}{\partial x}\right) d z+\left[K_{z} \frac{\partial S}{\partial z}\right]_{z_{n-1}} \\
-\left[w_{a} S\right]_{z_{n-1}}+S_{a} \quad \ldots \ldots \ldots \ldots \ldots \ldots \ldots \ldots \ldots . . . \cdots
\end{gathered}
$$

ここで $u, w$ は混相流の流速で, $w_{a}$ は気泡群の鉛直速 度である. 一般に $w_{a}$ は単一気泡の上昇速度よりやや小 さくなるのが普通である. $S_{a}$ は散気管から放出される 単位時間あたりの散気量 $Q_{a}$ を格子容積 $\Delta x \cdot \Delta z$ で割っ た值である.

$$
\begin{aligned}
& z=z_{k} \sim z_{k+1} \text { の任意の層では, } \\
& \frac{\partial}{\partial t} \int_{z_{k+1}}^{z_{k}} S d z=-\frac{\partial}{\partial x} \int_{z_{k+1}}^{z_{k}}(u S) d z-[w S]_{z_{k}} \\
& +[w S]_{z_{k+1}}+\frac{\partial}{\partial x} \int_{z_{k+1}}^{z_{k}}\left(K_{x} \frac{\partial S}{\partial x}\right) d z+\left[K_{z} \frac{\partial S}{\partial z}\right]_{z_{k}} \\
& -\left[K_{z} \frac{\partial S}{\partial z}\right]_{z_{k+1}}-\left[w_{a} S\right]_{z_{k}}+\left[w_{a} S\right]_{z_{k+1}}
\end{aligned}
$$

表面の癏では,

$$
\begin{aligned}
& \frac{\partial}{\partial t} \int_{z_{1}}^{\zeta} S d z=-\frac{\partial}{\partial x} \int_{z_{1}}^{\zeta}(u S) d z+[w S]_{z_{1}} \\
& +\frac{\partial}{\partial x} \int_{z_{1}}^{\zeta}\left(K_{x} \frac{\partial S}{\partial x}\right) d z-\left[K_{z} \frac{\partial S}{\partial z}\right]_{z_{1}}-\left[w_{a} S\right]_{\zeta} \\
& +\left[w_{a} S\right]_{z_{1}}
\end{aligned}
$$

となる. ここで右辺の $-\left[w_{a} S\right]_{\zeta}$ は水面から消失する空 気量を示すただし，気体は圧力，温度によって容積が 変化するので, 状態方程式

$$
\frac{p V}{T}=\frac{p_{\mathrm{atm}} V_{\mathrm{atm}}}{T_{\mathrm{atm}}}
$$

を用い， $S$ の計算では表面における $S=S_{0}$ の值で計算 を行ない，これを状態方程式で換算して $S$ を求めるよ うにする.ここで atm の記号は表面の状態を表わす.

次に $x$ 方向の運動量方程式から誘導し, 任意の層で 積分した表現を用いると，

$$
\begin{aligned}
& \frac{\partial}{\partial t} \int_{z_{k+1}}^{z_{k}}(\rho u) d z+\frac{\partial}{\partial x} \int_{z_{k+1}}^{z_{k}}\left(\rho u^{2}\right) d z+[\rho u w]_{z_{k}} \\
& \quad-[\rho u w]_{z_{k+1}}=-\frac{\partial}{\partial x} \int_{z_{k+1}}^{z_{k}} p d z \\
& \quad+\frac{\partial}{\partial x} \int_{z_{k+1}}^{z_{k}}\left(\mu_{x} \frac{\partial u}{\partial x}\right) d z+\left[\mu_{z} \frac{\partial u}{\partial z}\right]_{z_{k}} \\
& \quad-\left[\mu_{z} \frac{\partial u}{\partial z}\right]_{z_{k+1}} \ldots \ldots \ldots \ldots \ldots \ldots \ldots \ldots \ldots \ldots \ldots \ldots \ldots \ldots \ldots \ldots \ldots \ldots \ldots
\end{aligned}
$$

が得られる.

$z$ 方向の混相流の流速は, 今まで連続方程式の積分形

$$
[\rho w]_{z_{k}}=[\rho w]_{z_{k+1}}-\frac{\partial}{\partial t} \int_{z_{k+1}}^{z_{k}} \rho d z
$$

$$
-\frac{\partial}{\partial x} \int_{z_{k+1}}^{z_{k}}(\rho u) d z
$$

を用いていたが，今回は直接的に運動量方程式を取扱う 方法を採用した，すなわち，任意の $z=z_{k}$ におけるレ ベル面で考えれば， $x=x_{i} \sim x_{i+1}$ の区間で積分形をつく り,

$$
\begin{aligned}
& \frac{\partial}{\partial t} \int_{x_{i}}^{x_{i+1}}(\rho w) d x+[\rho u w]_{x_{i+1}}-[\rho u w]_{x_{i}} \\
& +\frac{\partial}{\partial z} \int_{x_{i}}^{x_{i+1}}\left(\rho w^{2}\right) d x=-\int_{x_{i}}^{x_{i+1}} \rho g d x \\
& -\frac{\partial}{\partial z} \int_{x_{i}}^{x_{i+1}} p d x+\left[\mu_{x} \frac{\partial w}{\partial x}\right]_{x_{i+1}}-\left[\mu_{x} \frac{\partial w}{\partial x}\right]_{x_{i}} \\
& +\frac{\partial}{\partial z} \int_{x_{i}}^{x_{i+1}}\left(\mu_{z} \frac{\partial w}{\partial z}\right) d x
\end{aligned}
$$

底面 $z=-h$ において

$$
w=0
$$

水面 $z=\zeta$ において

$$
w=\frac{\partial \zeta}{\partial t}+[u]_{\zeta} \frac{\partial \zeta}{\partial x}
$$

と表わされる. 式（13）に用いられるらは，連続式を表 層に適用してその格子内の密度を $\bar{\rho}$ とするとき,

$$
\bar{\rho} \frac{\partial \zeta}{\partial t}=[\rho w]_{z_{1}}-\left(\zeta-z_{1}\right) \frac{\partial \bar{\rho}}{\partial t}-\frac{\partial}{\partial x} \int_{z_{1}}^{\zeta}(\rho u) d z \cdots
$$

から得られる.

ここで注意すべきことは，式 (9), (11) などで求めら れる $u, w$ は混相流の連続式

$$
\frac{\partial \rho}{\partial t}+\frac{\partial}{\partial x}(\rho u)+\frac{\partial}{\partial z}(\rho w)=0
$$

を必ずしも満たすことにはならない.そこで式（15）を 満たすように $u, w, p$ の修正をはかる必要があり，そ れを逐次近似法の手段によって修正する，その方法を説 明すると次のようになる。

まず圧力は静水圧分布を仮定し，時間ステップを $n$, $x$ 方向のステップを $i, z$ 方向のそれを $k$ とし, これら の中間を $1 / 2$ で表示すると，

$$
\begin{aligned}
& p_{i+1 / 2, k+1 / 2}^{n+1 / 2}=\left(\zeta_{i+1 / 2}^{n+1 / 2}-z_{1}\right) \rho_{i+1 / 2,1 / 2}^{n+1 / 2} g \\
& \quad+\sum_{k=2}^{k}\left(z_{k-1}-z_{k}\right) \rho_{i+1 / 2, k-1 / 2}^{n+1 / 2} g \\
& \quad+\left(z_{k}-z_{k+1 / 2}\right) \rho_{i+1 / 2, k+1 / 2}^{n+1 / 2} g \ldots \ldots \ldots
\end{aligned}
$$

とおかれる. 次に式 (9) の左辺第 1 項と右辺第 1 項を差 分化し，他の項は残余の項として $R_{i}$ と表わせば,

$$
\begin{aligned}
& \left(\rho^{n+1 / 2} \cdot u^{n+1}\right)_{i, k+1 / 2}=-\frac{\Delta t}{\Delta x}\left\{p_{i+1 / 2, k+1 / 2}^{n+1 / 2}\right. \\
& \left.-p_{i-1 / 2, k+1 / 2}^{n+1 / 2}\right\}+R_{i} \\
& \left(\rho^{n+1 / 2} \cdot u^{n+1}\right)_{i+1, k+1 / 2}=-\frac{\Delta t}{\Delta x}\left\{p_{i+3 / 2, k+1 / 2}^{n+1 / 2}\right. \\
& \left.-p_{i+1 / 2, k+1 / 2}^{n+1 / 2}\right\}+R_{i+1}
\end{aligned}
$$

次に式 (11) の左辺第 1 項と右辺第 2 項とを差分化し, 
残余の項を $R_{k}$ とすれば，

$$
\begin{aligned}
& \left(\rho^{n+1 / 2} w^{n+1}\right)_{i+1 / 2, k}=-\frac{\Delta t}{\Delta z}\left\{p_{i+1 / 2, k-1 / 2}^{n+1 / 2}\right. \\
& \left.-p_{i+1 / 2, k+1 / 2}^{\stackrel{+}{*}}\right\}+R_{k} \\
& \left(\rho^{n+1 / 2} w^{n+1}\right)_{i+1 / 2, k+1}=-\frac{\Delta t}{\Delta z}\left\{p_{i+1 / 2, k+1 / 2}^{n+1 / 2}\right. \\
& \left.-p_{i+1 / 2, k+3 / 2}^{n+1 / 2}\right\}+R_{k+1}
\end{aligned}
$$

ところで式（15）の左辺第 2 項，第 3 項は次のように表 わされる。

$$
\begin{aligned}
\frac{\partial(\rho u)}{\partial x}= & \frac{1}{\Delta x}\left\{\left(\rho^{n+1 / 2} u^{n+1}\right)_{i+1, k+1 / 2}\right. \\
& \left.-\left(\rho^{n+1 / 2} u^{n+1}\right)_{i, k+1 / 2}\right\} \\
\frac{\partial(\rho w)}{\partial z}= & \frac{1}{\Delta z}\left\{\left(\rho^{n+1 / 2} w^{n+1}\right)_{i+1 / 2, k}\right. \\
& \left.-\left(\rho^{n+1 / 2} \cdot w^{n+1}\right)_{i+1 / 2, k+1}\right\}
\end{aligned}
$$

したがって，式（19）に式（17），(18）を代入し，残余の 項を全て $R$ と表わせば,

$$
\begin{aligned}
& \frac{\partial(\rho u)}{\partial x}+\frac{\partial(\rho w)}{\partial z}=2 \Delta t\left\{\frac{1}{(\Delta x)^{2}}+\frac{1}{(\Delta z)^{2}}\right\} p_{i+1 / 2, k+1 / 2}^{n+1 / 2} \\
& \quad+R
\end{aligned}
$$

となる. 式 (20) で $p_{i+1 / 2, k+1 / 2}^{n+1 / 2}$ に正の誤差が含まれる ときは，Rの影響を小さいものとすると直接的に左辺は 正の增分となって表われる．これより，両者の符号が逆 となるように, $\frac{\partial(\rho u)}{\partial x}+\frac{\partial(\rho w)}{\partial z}$ の変分に負の符号をつ ければ，圧力に生ずる誤差は修正される方向に動く．残 余の項の影響を含めて修正係数を $\alpha$ とし,式 (16) からの 圧力に対する修正值を $\delta p_{i+1 / 2, k+1 / 2}^{n+1 / 2}$ とおくと，

$$
\begin{aligned}
& \delta p_{i+1 / 2, k+1 / 2}^{n+1 / 2}=-\frac{1}{\left(\frac{1}{(\Delta x)^{2}}+\frac{1}{(\Delta z)^{2}}\right)} \frac{\alpha}{2 \Delta t} \\
& \quad \times\left[\frac{\rho_{i+1 / 2, k+1 / 2}^{n+1 / 2}-\rho_{i+1 / 2, k+1 / 2}^{n-1 / 2}}{\Delta t}\right. \\
& \left.+\frac{1}{\Delta x}\left\{\rho^{n+1 / 2} u^{n+1}\right)_{i+1, k+1 / 2}-\left(\rho^{n+1 / 2} u^{n+1}\right)_{i, k+1 / 2}\right\} \\
& \quad+\frac{1}{\Delta z}\left\{\left(\rho^{n+1 / 2} w^{n+1}\right)_{i+1 / 2, k}\right. \\
& \left.-\left(\rho^{n+1 / 2} w^{n+1}\right)_{i+1 / 2, k+1}\right] \ldots \ldots \ldots \ldots \ldots \ldots \ldots(21)
\end{aligned}
$$

と示される. $\alpha$ は一般に $1.5 \sim 1.9$ 程度で, 逐次近似の 方法は次のような操作となる。

（i）式（16）で示される圧力を用い，式（9)，(11）な どの計算を行ない， $u, w$ の值を算定する.

（ii）次にいま求められた $u, w$ を用いて式（21）へ代 入し，圧力の修正值 $\delta p$ を算出する。

(iii）この修正值を式（16）の圧力に適用して新たに $p$ を求め, この圧力によって再び式 (9), (11) などか ら $u, w$ を求める. （iv）これを再び式（21）へ代入して $\delta p$ を算出し，さ きの圧力 $p$ を修正する.

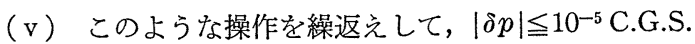
単位になるまで逐次計算を行なう。

上記の方法は水域全体の各格子で同時に行なうもの で，およそ 30 50 回の iteration で収束する結果が得ら れる. かくして確認された $u_{i, k+1 / 2}^{n+1 / 2}, w_{i+1 / 2, k}^{n+1}$ の值を用 い，式 (6)，(7)，(8) へ代入して $S_{i+1 / 2, k+1 / 2}^{n+3 / 2}$ の值を求 め, 式 (5) より $\rho_{i+1 / 2, k+1 / 2}^{n+3 / 2}$ を算定する. この密度分布 から式（16）の仮想的圧力を導き，上述の計算法でタイ ム・ステップを一つ進めた $u_{i, k+1 / 2}^{n+2}, w_{i+1 / 2, k}^{n+2}$ の流速を 求めるようにするものである.

式 (6)，(7)，(8) に含まれる拡散係数は気泡の拡がり に対応するもので, 実験室での再現には $10^{1} \sim 10^{2}$ C.G.S. 単位のオーダー, 現地では $10^{2} \sim 10^{3}$ C.G.S. 単位の值が 用いられよう。ここで問題となるのは式 (9), (11) なぞ に含まれる渦粘性係数 $\mu_{x}, \mu_{z}$ の值である. 水力学の研 究成果をみると，鉛直管路での上昇二相流の摩擦損失は 図一2のように示されている。

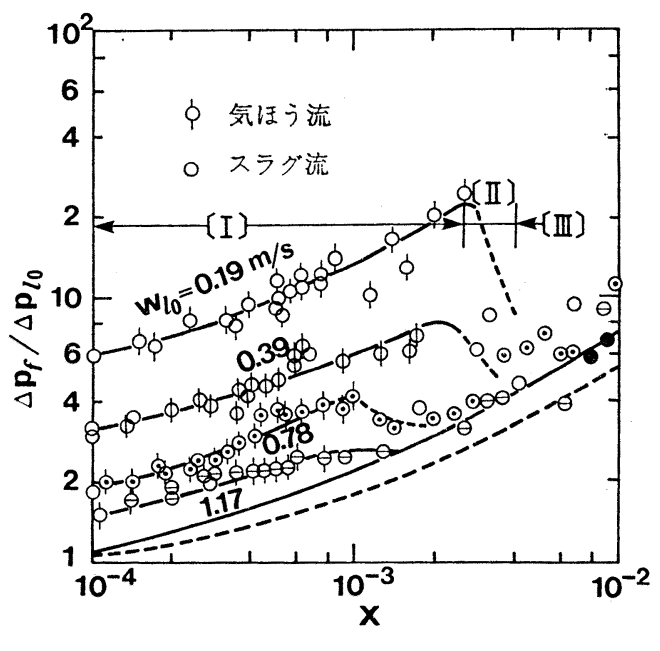

图一2 摩擦損失と流動様式

図一2 の横軸は式 (4) の乾き度を示し, 緃軸は単相流 の々の損失水頭に対する二相流の損失水頭の比を表わし ている. 二相流の上昇流速が小さいとき 10 倍程度, 大きいときでも数倍のエネルギー損失をもたらす結果を 示している. したがって本論が対象とする空気混相流の 場合でも，散気管近傍から上部の混相領域では，液体の みの単相流域に比して数倍のエネルギー損失となるよう にはかる必要があるう。

\section{3. シミュレーションの検討}

Kobus は幅 $1 \mathrm{~m}$, 長さ $10 \mathrm{~m}$, 水深 $2 \mathrm{~m}$ の水域で, 空気量を $V_{0}=30,62,100 \mathrm{~cm}^{3} / \mathrm{cm}-\mathrm{sec}$ としたときの実 


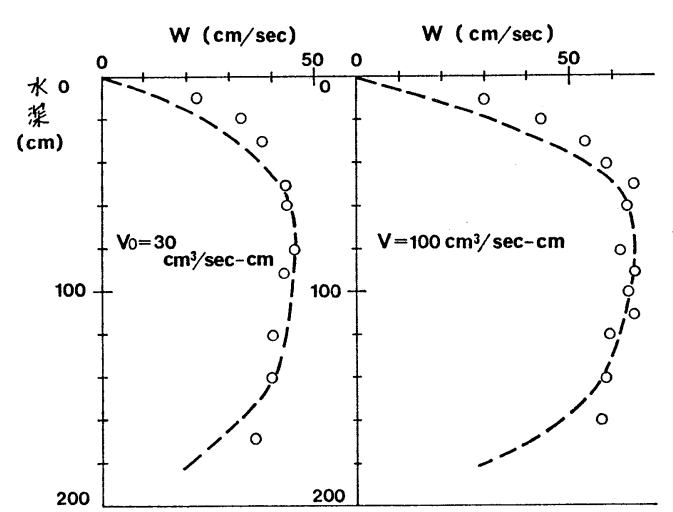

図-3 鉛直流速の比較

験結果を示している. その結果から, 散気管直上部の 各レベル面で得られる混相流の鉛直上昇速度の計算値と Kobus の実測值を比較してみると図一3のようになる.

計算は Kobus の実験水域と全く同様にとり，水深は 10 層に分割し, 散気管の周辺では一辺が $20 \mathrm{~cm}$ の正方 形格子となし, 散気管より十分に離れたところで長方形 の variable mesh につなゲている. 計算の安定のために $\Delta t=0.01 \mathrm{sec}$ としている. $V_{0}=30 \mathrm{~cm}^{3} / \mathrm{cm}-\mathrm{sec}$ のとき, C.G.S. 単位で $K_{x}=50 \sim 100, K_{z}=50$ の值をとり, $\mu_{x}$, $\mu_{z}$ は散気管の上部近傍において, 底面から，150，1000, 1900 と増大させ, 水面近くなって 1900 から 1000 , 500，50，0 と減少させるようにした。 それ以外の領域で は $150 \sim 180$ 程度である. $V_{0}=100 \mathrm{~cm}^{3} / \mathrm{cm}-\mathrm{sec}$ のとき は, $K_{x}=200, K_{z}=100$ としており, $\mu_{x}, \mu_{z}$ は前者と 同様な值を用いている.

図-4 は $V_{0}=30 \mathrm{~cm}^{3} / \mathrm{cm}-\mathrm{sec}$ のとの流れのパターン を表わしており， $\Delta t$ の 2000 3000 ステップ程度でか かる結果が得られる，図でみるように，表面からほぼ $1 / 4$ 水深の附近で, 水平流速は方向が逆転することがわ

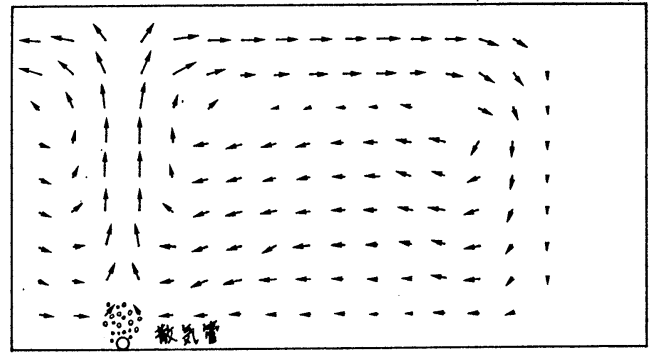

図一4 混相流による流れ

かる．図-4 は対称となる流況の片側を示したものであ る.

図一5 は現地での混相流の流況を試算的に再現したも のである. 水深を $20 \mathrm{~m}$ として 20 層に等分割し, 横方 向には $100 \mathrm{~m}$ の空間をもたせ，これにダブル・エアカー テンを発生させるため，散気管を $10 \mathrm{~m}$ の間隔で 2 本設 置したものである.この水域にはあらかじめ流れを与え ておき，表層から第 14 凮まで $-10 \mathrm{~cm} / \mathrm{sec，それより}$ 順次下層に対して $-9,-8,-7,-6,-5,-4 \mathrm{~cm} / \mathrm{sec}$ の流速を全体に分布させておく．2本の散匃量はともに $30 \mathrm{~cm}^{3} / \mathrm{cm}$-sec とし, 散気管近傍上部の $\mu_{x}, \mu_{z}$ は C.G.S. 単位で底面から 50，100，150，180，700，1900 と増大 させ，表面近くなってから 1900 より減じて 700, 180, 150，100，50，0 としており，他の領域では 50 180の 範囲の值を与えている. $K_{x}$ は $50 \sim 100, K_{z}$ は 50 とし ており， $\Delta t=0.02 \mathrm{sec}$ で計算している.

図からみるように，混相流の流孔は全体的に左側へ寄 せられており, 右側の散気管から生ずる下降流の一つ が，左側の散気管の上昇流の一つを圧迫し，このため， 左側へ寄せられた一つの旋回流を形成していることが判 明する.

現地での渦粘性係数は，流れに対応してオーダーとし

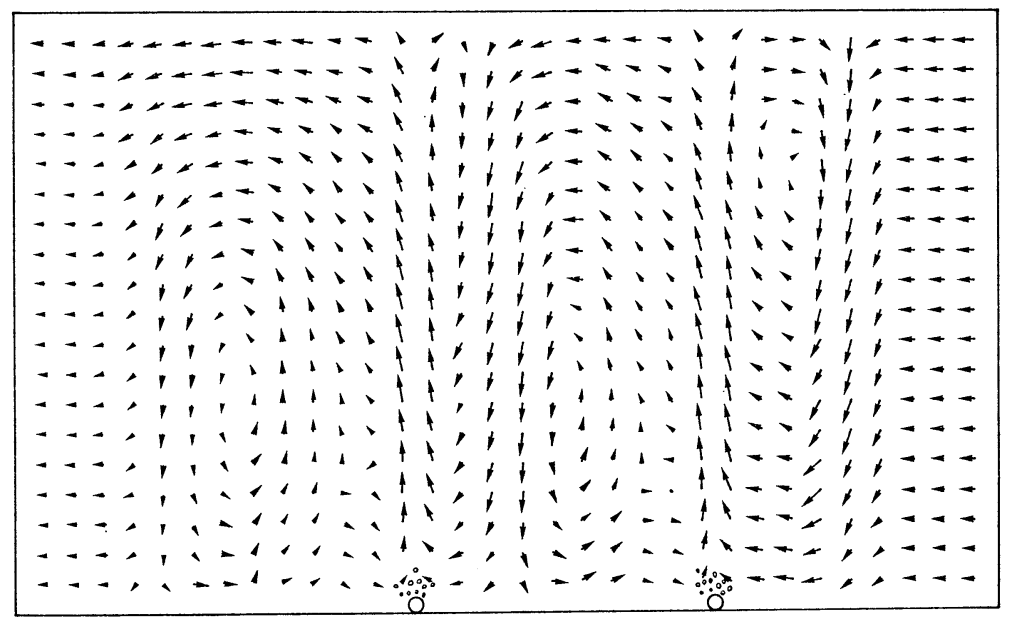

図一5 ダブル・エアカーテンによる流れの計算結果 
て值を判断することはできるが，やはり試行錯誤を絽返 えして近似することが，現段階では必要となろう。な お，このような計算の範囲では，ボイド率 $S$ は散気管 の直上で $10^{-2} \sim 10^{-3}$, それより離れると $10^{-3} \sim 10^{-4}$ の オーダとなり，後者の領域では，近似的に単相流とみな すこともできよう.
参考文 献

1）赤川浩爾：気液二相流, 機械工学大系, 11, コロナ社, 1982.

2) Kobus, H. E.: Analysis of the flow induced by airbubble systems, Coastal Eng. Con., pp. 1016 1031, London, 1968.

3）堀口孝男： 空気混相流による水質改善の現地実験とその解 析, 第 29 回海岸工学論文集, 土木学会, 1982. 